\title{
Torkildsen shunt as an option for hydrocephalus associated with optic pathway glioma: case report
}

\author{
Aldo José F da Silva
}

Pediatric Neurosurgery, General State Hospital, Pediatric Neurosurgery Division, Santa Mônica Teaching Maternity - Alagoas State University of Health Sciences, Maceió, Alagoas, Brazil

To whom correspondence should be addressed:

Aldo José F. da Silva

e-mail: neuroajfs@bol.com.br

Available at:

http://www.archpedneurosurg.com.br/
Hydrocephalus caused by optic pathway glioma (OPG) is most often treated with a ventriculoperitoneal shunt (VPS), but this treatment may present complications such as ascites. Hence, ventriculocisternal shunt is an option worth considering. This article reports a case in which it was decided to place a ventriculocisternal or Torkildsen shunt in a patient with hydrocephalus caused by OPG. Case Report: A 12-year-old girl, amaurotic, with a VPS due to hydrocephalus caused by an OPG, reported to the emergency room with abdominal distension and pain and difficulty in walking. Computed tomography of the abdomen was performed, and a large amount of fluid was evidenced in the peritoneal cavity (ascites). Liver and kidney functions were normal. In the surgical procedure, the distal extremity of the ventriculoperitoneal catheter was exposed, and $3 \mathrm{~L}$ of ascites fluid of cerebrospinal origin was drained. After 10 days of antibiotic therapy, a ventriculocisternal or Torkildsen shunt was placed. After 4 years of follow-up, the patient has no complaints. Discussion: Arne Torkildsen was the first to perform a ventriculocisternal shunt in 1937; it is indicated in cases of hydrocephalus with obstruction of the aqueduct or third ventricle. In OPG, increased protein levels in CSF and the use of platinum-based chemotherapy agents would explain the development of ascites after VPS placement. In these cases of hydrocephalus with third ventricle tumor infiltrating the hypothalamus, the ventriculocisternal shunt can be used as an option in specific cases.

Keyworks: Ascites, cerebrospinal fluid, glioma, hydrocephalus, ventriculoperitoneal shunt

\section{INTRODUCTION}

Hydrocephalus is one of the possible complications of optic pathway gliomas (OPGs). Ventriculoperitoneal shunts (VPS) are often used, but, albeit infrequently, some patients who receive them may develop ascites [1]. Ventriculocisternal or Torkildsen shunts could be a viable option to avoid this problem.

This is the case report of a child diagnosed with OPG and a VPS that progressed to ascites. It was then chosen to use a Torkildsen shunt to resolve the hydrocephalus.

\section{Case Report}

A 12-year-old girl, amaurotic, with a VPS due to obstructive hydrocephalus caused by an optic pathway glioma (Figure 1a), reported to the emergency room with abdominal distension and pain and difficulty in walking. A previous biopsy had diagnosed a pilocytic astrocytoma, and the patient had undergone several radio and chemotherapy sessions. A computed tomography of the abdomen showed a large amount of ascitic fluid in the peritoneal cavity (Figure 1b). Her liver and kidney functions were normal. During the surgical procedure, the distal extremity of the ventriculoperitoneal catheter was exposed (Figure 1c) and $3 \mathrm{~L}$ 


\section{Torkildsen shunt as an option for hydrocephalus associated with optic pathway glioma: case report}

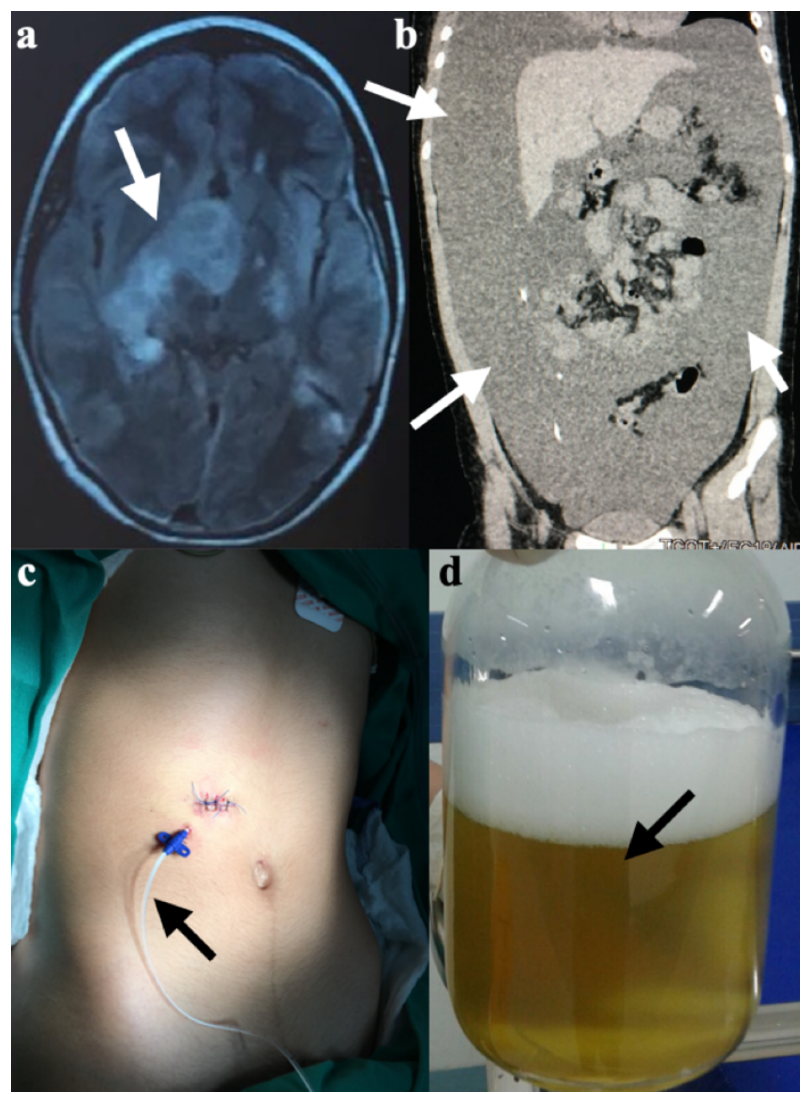

Figure 1 - (a) FLAIR (Fluid Acquisition Inversion Recovery) Magnetic Resonance sequence showing the optic-pathway glioma (white arrow); (b) Non-contrast coronal computed tomography of the abdomen showing ascites (white arrows); (c) Exposure of the distal extremity of the ventriculoperitoneal catheter in the abdomen; (d) Drained ascitic fluid (black arrow)

of citrus-yellow liquid was drained (Figure 1d). The analysis of the ascitic CSF showed glucose $40 \mathrm{mg} / \mathrm{dL}$, protein 820 $\mathrm{mg} / \mathrm{dL}, 20$ leukocytes/mm3, negative culture, and absence of neoplastic cells. After 10 days of antibiotic treatment, the CSF showed glucose $50 \mathrm{mg} / \mathrm{dL}$, protein $496 \mathrm{mg} / \mathrm{dL}, 10$ leukocytes/mm3, and negative culture.

It was decided to place a ventriculocisternal or Torkildsen shunt (Figure 2). In this surgical procedure, the patient is placed in a prone position under general anesthesia, and then a median longitudinal suboccipital incision with a left parieto-occipital trepanation orifice is performed followed by a ventricular puncture using a catheter without reservoir. After performing a small suboccipital craniectomy, the dura mater is exposed in the region of the foramen magnum, and a small incision is made in the midline of the dura mater through which the other extremity of the catheter is introduced (approximately $2 \mathrm{~cm}$ ) in the dorsolateral

direction from the spinal cord. C1 laminectomy is deemed unnecessary.
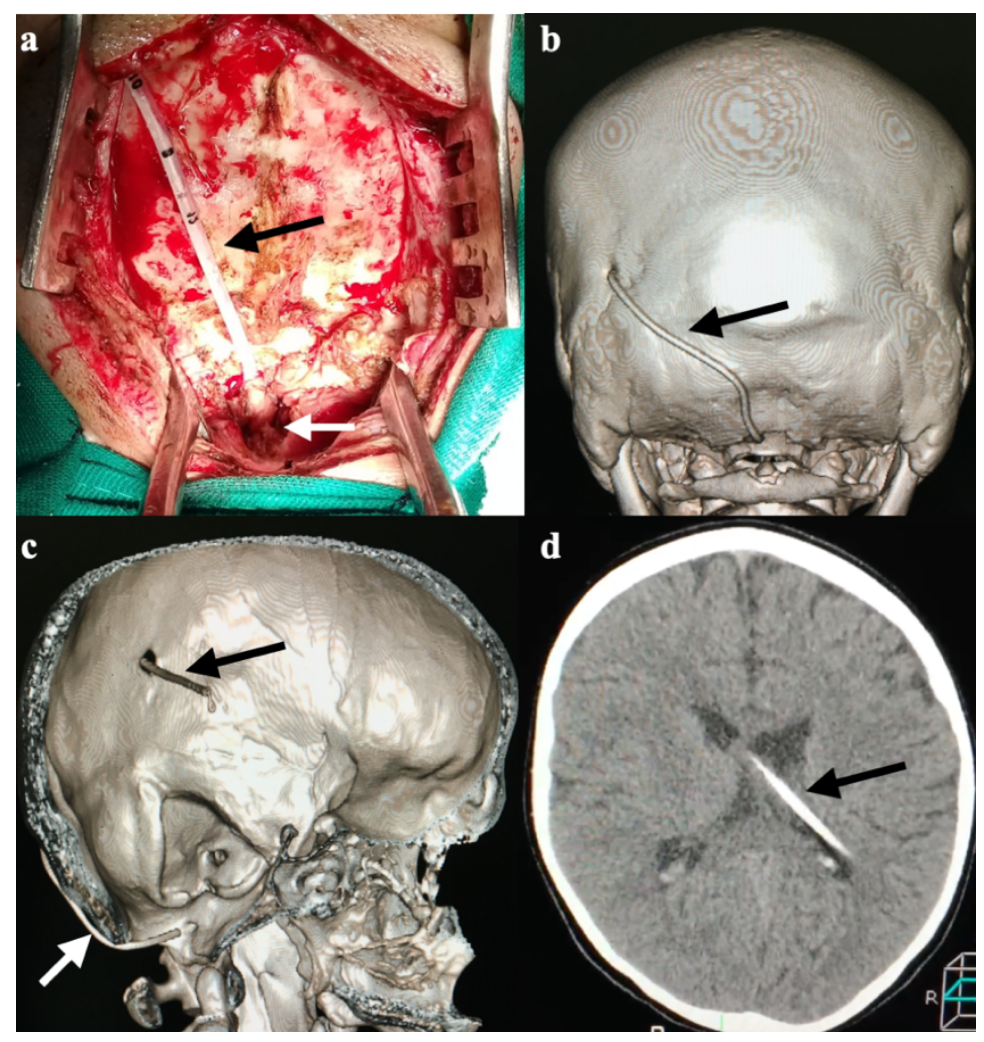

d

Figure 2 - (a) Ventriculocisternal shunt (black arrow), cisterna magna (white arrow); (b) and (c) Computed-tomography 3D reconstruction showing the Torkildsen shunt; (d) Non-contrast axial computed tomography of the skull showing the catheter in the ventricle (black arrow)

The surgery was performed without complications. The patient had a good postoperative course and was discharged from the hospital on the third day. During the outpatient follow-up for 4 years after the surgery, the patient remained well, without headache or vomiting.

\section{DISCUSSION}

Arne Torkildsen, a Norwegian neurosurgeon, was the first to implant a cerebrospinal fluid (CSF) shunt from the lateral ventricle into the cisterna magna in 1937; however, this technique was only published in 1939. This procedure is restricted to noncommunicating hydrocephalus caused by aqueductal stenosis, pituitary tumors, or infiltrating third ventricle tumors [2]. In the present case, there was an opticpathway glioma with infiltration of the hypothalamus and third ventricle.

Torkildsen reported a failure rate of $46 \%$ and mortality rate of $31 \%$ in his series of cases. In 1955, Paine and McKissock [3] published satisfactory results in $73 \%$ of cases and $20 \%$ of mortality. In 1963, Scarff [4] published a series of 136 cases 


\section{Torkildsen shunt as an option for hydrocephalus associated with optic pathway glioma: case report}

with a success rate of $58 \%$. The main advantage of Torkildsen's shunt is to allow physiological drainage of the CSF, thus avoiding the complications caused by ventriculoperitoneal shunt, whereas the disadvantage of Torkildsen's technique is that it is not possible to check the function of the shunt because there is no reservoir in the drainage catheter. Further, this type of shunt may lead to some complications, such as myelopathy due to spinal-cord injury caused by the tip of the catheter, catheter obstruction due to torsion, catheter migration, and sudden death due to catheter penetration into the cervicomedullary junction $[5,6]$.

Ascites is one of the possible complications of VPS placement [7]. Some factors may be related to the development of ascites: Infection; Previous abdominal surgeries; Multiple shunt replacements; Peritoneal metastases through the CSF; Increased CSF protein levels; Use of platinum-based chemotherapy agents $[8,9]$.

In OPGs, some studies suggest that increased CSF protein levels would explain the development of ascites after VPS placement [8]. In astrocytomas, specific proteins called astroproteins are sometimes produced [10]. However, there are also cases in which ascites occurs even with normal or low CSF protein levels [7].

In the present case, after a VPS was placed, the patient developed ascites, which could be explained by increased CSF protein level or platinum-based chemotherapy agents, as mentioned in some studies, or even due to infection. In many cases, a conversion to a ventriculoatrial shunt would be indicated. However, in the present case, a ventriculocisternal or Torkildsen shunt was chosen, and a 4year follow-up revealed no problems.

Ascites is particularly prevalent in patients with an OPG and a VPS. Although Torkildsen's shunt is an old technique, in some specific situations, it is still helpful to solve the patient's hydrocephalus problem.

\section{CONFLICT OF INTEREST}

The author declares no conflict of interest.

\section{REFERENCES}

1. Gil Z, Beni-Adani L, Siomin V, Nagar H, Dvir R, Constantini S. Ascites following ventriculoperitoneal shunting in children with chiasmatic-hypothalamic glioma. Child's Nervous System. 2001 Jun 1;17(7):395-8. doi:10.1007/s003810100460

2. Morota N, Ihara S, Araki T. Torkildsen shunt: reevaluation of the historical procedure. Child's Nervous System. 2010 Dec;26(12):1705-10. doi:10.1007/s00381010-1182-2

3. Paine KW, Mckissock W. Aqueduct stenosis; clinical aspects, and results of treatment by ventriculocisternostomy (Torkildsen's operation). J Neurosurg. 1955 Mar;12(2):127-45. doi: 10.3171/jns.1955.12.2.0127. PMID: 14368344.

4. Scarff JE. Treatment of hydrocephalus: an historical and critical review of methods and results. J Neurol Neurosurg Psychiatry. 1963 Feb;26(1):1-26. doi: 10.1136/jnnp.26.1.1. PMID: 13976518; PMCID: PMC495530.

5. Alp MS: What is a Torkildsen shunt? Surgical Neurology. 1995 Apr;43(4):405-6. doi:10.1016/00903019(95)80075-r

6. Eide PK, Lundar T. Arne Torkildsen and the ventriculocisternal shunt: the first clinically successful shunt for hydrocephalus. Journal of Neurosurgery. 2016 May 1;124(5):1421-8. doi:10.3171/2015.1.JNS142659

7. Yount RA, Glazier MC, Mealey J Jr, Kalsbeck JE. Cerebrospinal fluid ascites complicating ventriculoperitoneal shunting: report of four cases. Journal of neurosurgery. 1984 Jul 1;61(1):180-3.

8. West GA, Berger MS, Geyer JR. Childhood optic pathway tumors associated with ascites following ventriculoperitoneal shunt placement. Pediatric Neurosurgery. 1994;21(4):254-9. doi:10.1159/000120846

9. Johnson JA, O'Halloran PJ, Crimmins D, Caird J. Thinking outside the shunt-sterile CSF malabsorption in pilocytic astrocytomas: case series and review of the literature. Child's Nervous System. 2016 Nov;32(11):2255-60. doi:10.1007/s00381-016-3112-4

10. Hayakawa T, Morimoto K, Ushio $Y$, et al. Levels of astroprotein (an astrocyte-specific cerebroprotein) in cerebrospinal fluid of patients with brain tumors. An attempt at immunochemical diagnosis of gliomas. J Neurosurgery 1980;52(2):229-33. doi:10.3171/jns.1980.52.2.0229 